\title{
KRAS, GNAS, and RNF43 mutations in intraductal papillary mucinous neoplasm of the pancreas: a meta-analysis
}

\author{
Ju-Han Lee, Younghye Kim, Jung-Woo Choi and Young-Sik Kim
}

\begin{abstract}
Background: The prevalence and clinical significances of KRAS, GNAS, and RNF43 mutations in patients with pancreatic intraductal papillary mucinous neoplasm (IPMN) remain elusive. To evaluate the incidence of the gene mutations and clinicopathologic differences between KRAS and GNAS mutations in pancreatic cystic lesions, we performed a meta-analysis of published 33 KRAS, 11 GNAS, and 4 RNF43 studies including 1253, 835, and 143 cases, respectively.

Methods: We pooled the results of relevant studies identified using the PubMed and EMBASE databases. The effect sizes of outcome parameters were computed by the prevalence rate, weighted mean difference, or odds ratio (OR) using a random-effects model.

Results: The pooled prevalence of KRAS, GNAS, and RNF43 mutations in IPMN was 61, 56, and $23 \%$, respectively. The KRAS (OR 7.4 and 71.2) and GNAS (OR 30.2 and 15.3) mutations were more frequently found in IPMNs than in mucinous cystic neoplasms and in serous cystadenomas, respectively. Of the microscopic subtypes of IPMN, KRAS and GNAS were frequently mutated in gastric type (OR 2.7, $P<0.001)$ and intestinal type (OR 3.0, $P<0.001)$, respectively. KRAS mutation was infrequently found in high-grade dysplasia lesions of IPMN (OR 0.6, $P=0.032)$. GNAS mutation was associated with male (OR 1.9, $P=0.012$ ).

Conclusions: This meta-analysis supports that KRAS and GNAS mutations could be diagnostic markers for IPMN. In addition, the frequencies of KRAS and GNAS mutations in IPMNs are highly variable according to the microscopic duct subtypes, reflecting their independent roles in the IPMN-adenocarcinoma sequence.
\end{abstract}

Keywords: Intraductal papillary mucinous neoplasm, KRAS, GNAS, Meta-analysis

\section{Background}

Intraductal papillary mucinous neoplasm (IPMN) of the pancreas is a mucin-producing and cystic tumour growing inside the pancreatic duct and forming papillary projections (Klöppel et al. 2014; Klöppel and Kosmahl 2001). IPMN is considered as a precursor of pancreatic adenocarcinoma and comprised of about 16-24 \% of cystic pancreatic lesions (Klöppel et al. 2014; Klöppel and Kosmahl 2001). IPMN forms a multilocular cystic lesion and is difficult to distinguish from mucinous cystic neoplasm (MCN) (Klöppel et al. 2014; Klöppel and Kosmahl 2001).

\footnotetext{
${ }^{*}$ Correspondence: apysk@korea.ac.kr

Department of Pathology, Korea University Ansan Hospital, 123,

Jeokgeum-ro, Danwon-gu, Ansan-si, Gyeonggi-do 425-707, Republic of Korea
}

Recently, genetic studies of IPMN lead to discover mutations of new genes, including GNAS, and RNF43 (Macgregor-Das and Iacobuzio-Donahue 2013; Reid et al. 2014). In addition to the previously known genetic alteration such as KRAS, these gene mutations open a new viewpoint in the field of the molecular pathogenesis of IPMN. Nevertheless, the frequencies and clinicopathologic significances of KRAS, GNAS, and RNF43 have not been clearly delineated. Activating GNAS mutation at codon 201 has been identified in IPMNs of the pancreas, which runs from 36 to $79 \%$ (Amato et al. 2014; Hosoda et al. 2015; Ideno et al. 2015; Kanda et al. 2013; Kuboki et al. 2015; Lee et al. 2014; Siddiqui et al. 2013; Singhi et al. 2014; Takano et al. 2014; Tan et al. 2015; Wu et al. 2011b). Moreover, the wide extreme diversity of KRAS 
mutation in IPMN patients, ranged from 13 to $100 \%$, has been observed (Amato et al. 2014; Chadwick et al. 2009; Chang et al. 2014; Fritz et al. 2009; Furukawa et al. 2005; Hosoda et al. 2015; Ideno et al. 2015; Jang et al. 2009; Kaino et al. 1999; Kitago et al. 2004; Kobayashi et al. 2008; Kondo et al. 1997; Kuboki et al. 2015; Lee et al. 2014; Lubezky et al. 2011; Mizuno et al. 2010; Mohri et al. 2012; Mueller et al. 2003; Mulligan et al. 1999; Nakata et al. 2002; Paal et al. 1999; Raimondo et al. 2002; Schönleben et al. 2008; Sessa et al. 1994; Siddiqui et al. 2013; Singhi et al. 2014; Tada et al. 1991; Takano et al. 2014; Tan et al. 2015; Uemura et al. 2003; Wada et al. 2004; Wu et al. 2011b; Yoshizawa et al. 2002). The frequency of RNF43 mutation was ranged from 14 to $75 \%$ (Amato et al. 2014; Sakamoto et al. 2015; Tan et al. 2015; Wu et al. 2011a).

Therefore, in this meta-analysis, we aimed to know the exact prevalence of KRAS, GNAS, and RNF43 mutations in IPMN patients, and the difference between the frequency of these mutant genes in pancreatic cystic lesions. In addition, we investigated whether $K R A S$ and GNAS mutations have clinicopathologic significances in patients with IPMN.

\section{Methods}

\section{Data collection and selection criteria}

We searched PubMed (http://www.ncbi.nlm.nih.gov/ pubmed) and EMBASE (www.embase.com) using the keywords "KRAS", "GNAS", "RNF43", "pancreas" and "intraductal papillary mucinous neoplasm". We also manually searched the reference lists of the identified articles. Duplicate data or overlapping articles were excluded by examining the authors' names and affiliations. Original articles reporting cases of KRAS, GNAS, and RNF43 mutations published before June 2015 were included. When multiple articles were published by the same authors or institutions, the most recent or single informative article was selected. Articles lacking clinicopathologic data for meta-analysis, review articles without original data, conference abstracts, case reports, and articles that dealt with cell line or animal were excluded. In addition, immunohistochemical studies of $R A S$ mutation were also excluded. There were no geographic or language restrictions. The selection process of the articles is shown in Fig. 1.

\section{Data pooling and statistics}

Meta-analysis was performed as previously described (Lee et al. 2011). Briefly, effect sizes for each study were calculated by prevalence rate or odds ratio (OR) and the corresponding $95 \%$ confidence interval $(\mathrm{CI})$ using the Mantel-Haenszel method. The prevalence rate, weighted mean difference (WMD), or OR was combined using a random-effects model (DerSimonian-Laird method). Statistical heterogeneity among studies was evaluated using the Cochrane Q test and $I^{2}$ statistics. The $I^{2}$ statistic refers to the percentage of variation across studies that is due to heterogeneity rather than chance and does not inherently depend on the number of studies considered $\left[I^{2}=100 \% \times(\mathrm{Q}-\mathrm{df}) / \mathrm{Q}\right]$. We clarified the cutoff of $I^{2}$ statistics for assignment of low $(<25 \%)$, moderate (25$50 \%$ ), and high (>50\%) heterogeneities. If $I^{2}$ value was more than $50 \%$, subgroup analysis was done. Sensitivity analyses were performed to examine the influence of each study on the pooled prevalence rate, WMD, or OR by serially omitting an individual study and pooling the remaining studies. Publication bias was examined by funnel plots and Egger's tests for the degree of asymmetry. Publication bias was assumed to be present if the $P$ value was less than 0.1 . The pooled analysis was performed using Comprehensive Meta-analysis Software version 2.0 (Biostat, Englewood, NJ, USA).

\section{Results}

Thirty-three and eleven studies reported the frequencies of KRAS and GNAS mutations between 1253 and 835 IPMN patients, respectively (Tables 1, 2) (Amato et al. 2014; Chadwick et al. 2009; Chang et al. 2014; Fritz et al. 2009; Furukawa et al. 2005; Hosoda et al. 2015; Ideno et al. 2015; Jang et al. 2009; Kaino et al. 1999; Kanda et al. 2013; Kitago et al. 2004; Kobayashi et al. 2008; Kondo et al. 1997; Kuboki et al. 2015; Lee et al. 2014; Lubezky et al. 2011; Mizuno et al. 2010; Mohri et al. 2012; Mueller et al. 2003; Mulligan et al. 1999; Nakata et al. 2002; Paal et al. 1999; Raimondo et al. 2002; Schönleben et al. 2008; Sessa et al. 1994; Siddiqui et al. 2013; Singhi et al. 2014; Tada et al. 1991; Takano et al. 2014; Tan et al. 2015; Uemura et al. 2003; Wada et al. 2004; Wu et al. 2011b; Yoshizawa et al. 2002). On pooled analysis, KRAS and GNAS mutations were 60.9 \% (95\% CI 54.3-67.1) and $55.8 \%$ (95 \% CI 48.5-62.8) in IPMN patients (Table 3). The KRAS and GNAS mutations did not differ according to the ethnicity, detection methods, and specimen type (Table 3). Additionally, eight studies presented the cases having both KRAS and GNAS mutations (Amato et al. 2014; Hosoda et al. 2015; Kuboki et al. 2015; Lee et al. 2014; Siddiqui et al. 2013; Singhi et al. 2014; Tan et al. 2015; Wu et al. 2011b). On pooled analysis, $33.5 \%$ (95 \% CI 26.2-41.6) of IPMN patients harboured both KRAS and GNAS mutations. On the other hand, four studies (Amato et al. 2014; Sakamoto et al. 2015; Tan et al. 2015; Wu et al. 2011a) described the prevalence of RNF43 mutation among 143 IPMN patients (Additional file 1: Table S1). On pooled analysis, the frequency of RNF43 mutation was $22.9 \%$ (95 \% CI 10.8-42.4). 


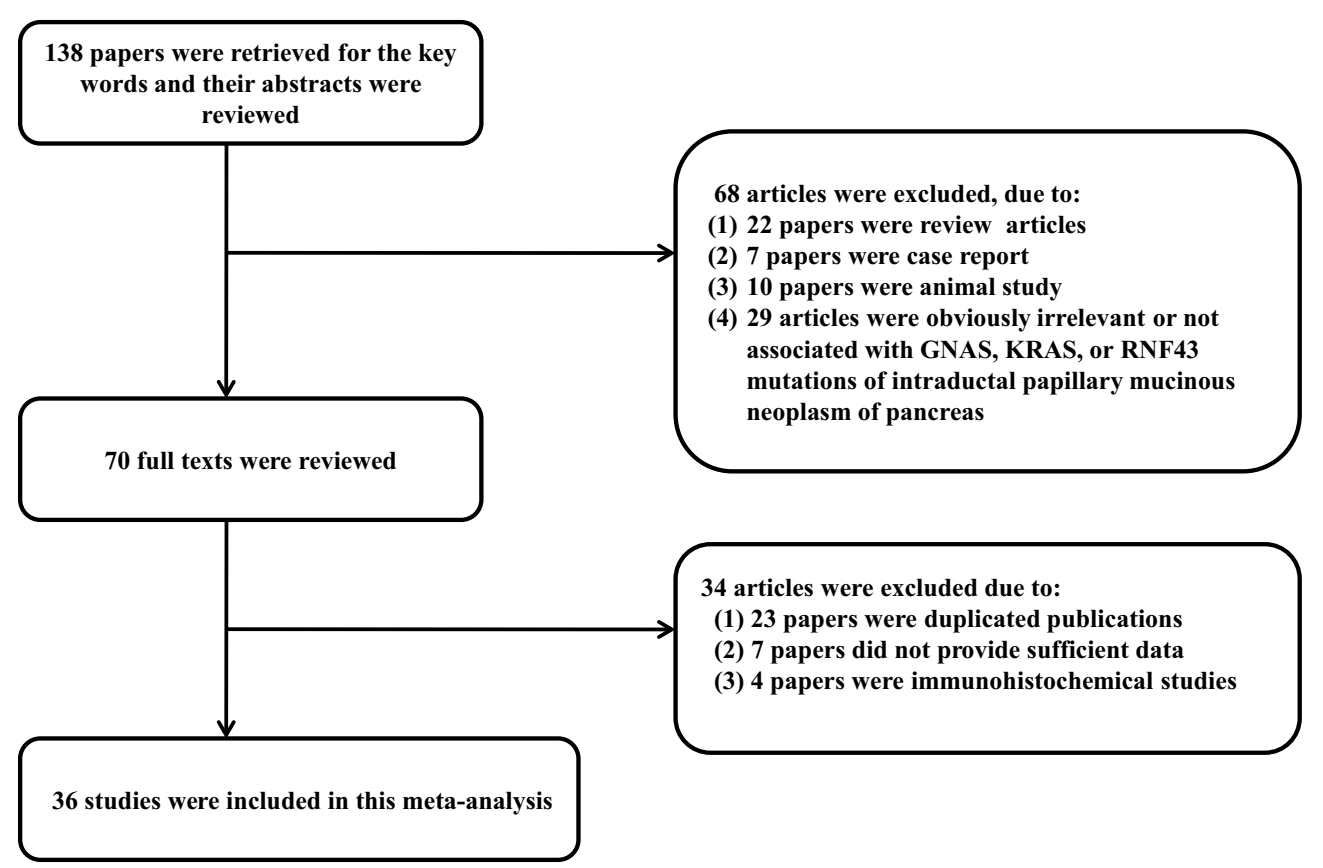

Fig. 1 Flow diagram of article selection for this meta-analysis

\section{Other cystic lesions}

Seven (Hosoda et al. 2015; Lee et al. 2014; Schönleben et al. 2008; Singhi et al. 2014; Uemura et al. 2003; Wu et al. 2011b; Yoshizawa et al. 2002) and four (Hosoda et al. 2015; Lee et al. 2014; Siddiqui et al. 2013; Wu et al. 2011b) studies presented KRAS and GNAS mutations between IPMN and MCN patients. KRAS mutation was found in 239 (69\%) of 345 IPMN and 14 (21\%) of 67 MCN patients. GNAS mutation was detected in 168 (58\%) of 292 IPMN and in none of $57 \mathrm{MCN}$. The overall ORs for KRAS and GNAS mutations in IPMN patients were 7.444 (95 \% CI 3.850-14.392; $P<0.001, \mathrm{Q}=4.540$, $\left.I^{2}=0.000\right)$ and 30.194 (95\% CI 7.143-127.622; $P<0.001$, $\left.\mathrm{Q}=0.787, I^{2}=0.000\right)$, compared with those mutations in $\mathrm{MCN}$, respectively (Fig. 2).

Four (Hosoda et al. 2015; Lee et al. 2014; Singhi et al. 2014; Wu et al. 2011b) and five (Hosoda et al. 2015; Kanda et al. 2013; Lee et al. 2014; Singhi et al. 2014; Wu et al. 2011b) studies addressed KRAS and GNAS mutations between IPMN and serous cystadenoma (SCA) patients, respectively. KRAS mutation was found in 210 (72\%) of 292 IPMN and none (0 \%) of 83 SCA patients. GNAS mutation was detected in 217 (59\%) of 370 IPMN patients and 2 ( $2 \%)$ of 82 SCA patients. The overall ORs for $K R A S$ and GNAS mutation in IPMN patients were 71.240 (95 \% CI 16.856-301.086; $P<0.001, \mathrm{Q}=1.810$, $\left.I^{2}=0.000\right)$ and 15.297 (95\% CI 4.544-51.498; $P<0.001$, $\left.\mathrm{Q}=4.525, I^{2}=11.611\right)$, respectively.

\section{Age and sex}

The incidence of KRAS and GNAS mutations in patients with IPMN according to the patient's sex was compared in eleven (Fritz et al. 2009; Hosoda et al. 2015; Kobayashi et al. 2008; Kondo et al. 1997; Mulligan et al. 1999; Schönleben et al. 2008; Singhi et al. 2014; Tada et al. 1991; Uemura et al. 2003; Wada et al. 2004; Wu et al. 2011b) and six (Hosoda et al. 2015; Ideno et al. 2015; Kanda et al. 2013; Singhi et al. 2014; Takano et al. 2014; Wu et al. 2011b) studies, respectively. KRAS mutation was detected in 162 (69\%) of 236 male patients and 120 (69\%) of 173 female patients with IPMN. GNAS mutation was detected in 198 (63\%) of 314 male patients and 110 (48 \%) of 229 female patients with IPMN. The overall ORs for KRAS and GNAS mutations in male patients with IPMN were 1.065 (95 \% CI 0.680-1.668; $P=0.782$, $\left.\mathrm{Q}=7.216, I^{2}=0.000\right)$ and 1.946 (95\% CI 1.156-3.278; $P=0.012, \mathrm{Q}=9.885, I^{2}=49.419$ ), respectively (Fig. 3 ).

Five (Fritz et al. 2009; Kobayashi et al. 2008; Schönleben et al. 2008; Singhi et al. 2014; Wada et al. 2004) and three (Kanda et al. 2013; Singhi et al. 2014; Wu et al. 2011b) studies presented mean age with standard deviation (SD) or $\mathrm{p}$ value according to KRAS and GNAS mutations, respectively. The mean age of IPMN patients with $K R A S$ mutation ranged from 63.67 to 70.15 years, whereas the mean age of those with wild-type $K R A S$ ranged from 64.3 to 68.58 years. The mean age of IPMN patients with GNAS mutation ranged from 62.14 to 69.54 years, 
Table 1 Characteristics of individual studies of KRAS mutation in patients with intraductal papillary mucinous neoplasm

\begin{tabular}{|c|c|c|c|c|c|}
\hline Study & Country & Ethnicity & Detection method & Specimen & KRAS mutation (\%) \\
\hline Amato $\mathrm{E}$ & Italy & Caucasian & Sequencing & Tissue & $24 / 48(50.0)$ \\
\hline Chadwick B & USA & Caucasian & Sequencing & Tissue & $37 / 52(71.2)$ \\
\hline Chang X & China & Asian & Sequencing & Tissue & 9/16 (56.3) \\
\hline Fritz S & USA & Caucasian & Sequencing & Tissue & $8 / 20(40.0)$ \\
\hline Furukawa T & Japan & Asian & ASH, sequencing & Tissue & 5/6 (83.3) \\
\hline Hosoda W & Japan & Asian & real-time $P C R$, sequencing & Tissue & $59 / 91(64.8)$ \\
\hline Ideno N & Japan & Asian & HRM, sequencing & Tissue & 75/95 (78.9) \\
\hline Jang JY & Korea & Asian & Sequencing & Tissue & $13 / 37(35.1)$ \\
\hline Kaino M & Japan & Asian & SSCP, sequencing & Pancreatic juice & $12 / 12(100.0)$ \\
\hline Kitago M & Japan & Asian & Sequencing & Tissue & $16 / 20(80.0)$ \\
\hline Kobayashi N & Japan & Asian & PCR/PHFA & Pancreatic juice & $13 / 22(59.1)$ \\
\hline Kondo H & Japan & Asian & SSCP, sequencing & Pancreatic juice & $12 / 13(92.3)$ \\
\hline KubokiY & Japan & Asian & Sequencing & Tissue & $96 / 172(55.8)$ \\
\hline Lee LS & USA & Caucasian & Sequencing & Tissue & 9/19 (47.4) \\
\hline Lubezky N & Israel & Caucasian & Sequencing & Tissue & 9/27 (33.3) \\
\hline Mizuno O & Japan & Asian & Semiquantitative PCR & Pancreatic juice & $43 / 53(81.1)$ \\
\hline Mohri D & Japan & Asian & Sequencing & Tissue & $14 / 25(56.0)$ \\
\hline Muller J & Germany & Caucasian & PCR-RFLP & Tissue & 4/13 (30.8) \\
\hline Mulligan NJ & USA & Caucasian & PCR & Tissue & 5/7 (71.4) \\
\hline Nakata B & Japan & Asian & SSCP, sequencing & Tissue & 19/26 (73.1) \\
\hline Paal E & USA & Caucasian & Sequencing & Tissue & $2 / 15(13.3)$ \\
\hline Raimondo M & USA & Caucasian & SSCP, sequencing & Tissue & $29 / 40(72.5)$ \\
\hline Schönleben F & USA & Caucasian & Sequencing & Tissue & $17 / 36(47.2)$ \\
\hline Sessa F & Italy & Caucasian & SSCP, sequencing & Tissue & 8/26 (30.8) \\
\hline Siddiqui AA & USA & Caucasian & Quantitative PCR & Cyst fluid & 6/9 (66.7) \\
\hline Singhi AD & USA & Caucasian & Sequencing & Cyst fluid & $35 / 50(70.0)$ \\
\hline Tada M & Japan & Asian & Sequencing & Tissue & $3 / 5(60.0)$ \\
\hline \multirow[t]{2}{*}{ Takano S } & Japan & Asian & Sequencing & Tissue & 6/6 (100.0) \\
\hline & & & & Pancreatic juice & $32 / 50(64.0)$ \\
\hline Tan MC & USA & Caucasian & Sequencing & Tissue & 27/38 (71.1) \\
\hline Uemura K & Japan & Asian & Sequencing & Tissue & 8/10 (80.0) \\
\hline Wada K & Japan & Asian & Sequencing & Tissue & $15 / 23(65.2)$ \\
\hline \multirow[t]{2}{*}{ Wu J } & USA & Caucasian & PCR/ligation & Tissue & 39/49 (79.6) \\
\hline & & & & Cyst fluid & 68/83 (81.9) \\
\hline Yoshizawa K & Japan & Asian & Sequencing & Tissue & 4/7 (57.1) \\
\hline
\end{tabular}

ASH allele-specific oligonucleotide hybridization, $P C R$ polymerase chain reaction, $H R M$ high-resolution melt-curve analysis, $S S C P$ single strand conformation polymorphism, PHFA preferential homoduplex formation assay, RFLP restriction fragment length polymorphism

whereas the mean age of those with wild-type GNAS ranged from 59 to 70.09 years. No associations were found between mean age and KRAS (WMD $=0.140$; $95 \% \mathrm{CI}-0.194$ to $0.475 ; P=0.410, \mathrm{Q}=2.940$, $\left.I^{2}=0.000\right)$ or GNAS (WMD $=0.099 ; 95 \% \mathrm{CI}-0.156$ to 0.354; $\left.P=0.448, \mathrm{Q}=1.838, I^{2}=0.000\right)$ mutations.

\section{Location and tumour size}

The incidence of KRAS or GNAS mutation in patients with IPMN according to the location (head versus body or tail) was compared in eight (Hosoda et al. 2015;
Kobayashi et al. 2008; Kondo et al. 1997; Schönleben et al. 2008; Singhi et al. 2014; Uemura et al. 2003; Wada et al. 2004; Wu et al. 2011b) and six (Hosoda et al. 2015; Ideno et al. 2015; Kanda et al. 2013; Singhi et al. 2014; Takano et al. 2014; Wu et al. 2011b) studies, respectively. KRAS mutation was detected in 154 (67\%) of 229 patients with IPMN arising in the pancreatic head and $97(75 \%)$ of 130 patients in the body or tail. GNAS mutation was detected in 168 (58\%) of 288 patients with IPMN arising in the pancreatic head and 125 (56\%) of 224 patients in the body or tail. There were no associations between KRAS 
Table 2 Characteristics of individual studies of GNAS mutation in patients with IPMN

\begin{tabular}{|c|c|c|c|c|c|}
\hline Study & Country & Ethnicity & Detection method & Specimen & GNAS mutation (\%) \\
\hline Amato $\mathrm{E}$ & Italy & Caucasian & Sequencing & Tissue & 38/48 (79.2) \\
\hline Hosada W & Japan & Asian & Real-time $P C R$, sequencing & Tissue & $55 / 91(60.4)$ \\
\hline Ideno N & Japan & Asian & HRM, sequencing & Tissue & $65 / 110(59.1)$ \\
\hline Kanda M & USA & Caucasian & HRM, pyrosequencing & Pancreatic juice & 49/78 (62.8) \\
\hline KubokiY & Japan & Asian & Sequencing & Tissue & $82 / 172(47.7)$ \\
\hline Lee LS & USA & Caucasian & Sequencing & Tissue & $8 / 19(42.1)$ \\
\hline Siddiqui AA & USA & Caucasian & Quantitative PCR & Cyst fluid & 4/9 (44.4) \\
\hline Singhi AD & USA & Caucasian & Sequencing & Cyst fluid & 18/50 (36.0) \\
\hline \multirow[t]{2}{*}{ Takano S } & Japan & Asian & Sequencing & Tissue & 4/6 (66.7) \\
\hline & & & & Pancreatic juice & $34 / 82(41.5)$ \\
\hline $\operatorname{Tan} M C$ & USA & Caucasian & Sequencing & Tissue & 23/38 (60.5) \\
\hline \multirow[t]{2}{*}{ Wu J } & USA & Caucasian & PCR/ligation & Tissue & $36 / 49(73.5)$ \\
\hline & & & & Cyst fluid & $51 / 83(61.4)$ \\
\hline
\end{tabular}

$P C R$ polymerase chain reaction, HRM high-resolution melt-curve analysis

Table 3 Prevalence of KRAS and GNAS mutations in patients with IPMN according to the ethnicity, mutation detection, and specimen type

\begin{tabular}{|c|c|c|c|c|c|c|c|c|}
\hline \multirow[t]{2}{*}{ Category } & \multicolumn{4}{|l|}{ KRAS mutation } & \multicolumn{4}{|l|}{ GNAS mutation } \\
\hline & No. of studies & No. of cases & $\begin{array}{l}\text { Prevalence (\%) } \\
(95 \% \mathrm{Cl})\end{array}$ & $P$ value & No. of studies & No. of cases & $\begin{array}{l}\text { Prevalence (\%) } \\
(95 \% \mathrm{Cl})\end{array}$ & $P$ value \\
\hline Overall & 33 & 1253 & $60.9(54.3-67.1)$ & & 11 & 835 & $55.8(48.5-62.8)$ & \\
\hline Ethnicity & & & & 0.106 & & & & 0.429 \\
\hline Caucasian & 15 & 532 & $55.1(45.2-64.7)$ & & 7 & 374 & $58.4(48.8-67.4)$ & \\
\hline Asian & 18 & 721 & $66.0(56.9-74.0)$ & & 4 & 461 & $52.6(41.8-63.1)$ & \\
\hline Detection method & & & & 0.207 & & & & 0.552 \\
\hline Sequencing & 27 & 1017 & $59.0(52.1-65.6)$ & & 9 & 694 & $54.9(47.0-62.5)$ & \\
\hline Non-sequencing & 6 & 236 & $69.0(54.6-80.4)$ & & 2 & 141 & $60.9(42.3-76.9)$ & \\
\hline Specimen type ${ }^{a}$ & & & & 0.095 & & & & 0.147 \\
\hline Tissue & 27 & 929 & $58.9(51.3-66.1)$ & & 8 & 533 & $61.0(52.0-69.4)$ & \\
\hline $\begin{array}{l}\text { Cyst fluid or pancre- } \\
\text { atic juice }\end{array}$ & 8 & 324 & $71.4(58.4-81.7)$ & & 5 & 302 & $50.3(39.1-61.5)$ & \\
\hline
\end{tabular}

or GNAS mutation and tumour location (OR 0.836, $95 \%$ CI $0.477-1.465, P=0.532, Q=7.624, I^{2}=8.182$ and OR 1.133, $95 \%$ CI 0.785-1.634, $P=0.505, Q=2.131$, $I^{2}=0.000$, respectively).

Four (Kanda et al. 2013; Kuboki et al. 2015; Singhi et al. 2014; Wu et al. 2011b) and three (Kuboki et al. 2015; Singhi et al. 2014; Wada et al. 2004) studies presented mean tumour size with SD or $\mathrm{p}$ value according to KRAS or GNAS mutation, respectively. The average tumour size of IPMN patients with KRAS mutations ranged from 2.4 to $2.9 \mathrm{~cm}$, whereas the mean size of IPMNs with wild-type $K R A S$ ranged from 2.51 to $2.86 \mathrm{~cm}$. The mean tumour size of IPMNs with GNAS mutation ranged from 1.234 to $3.859 \mathrm{~cm}$, whereas the average size of IPMNs with wild-type GNAS ranged from 1.134 to $3.66 \mathrm{~cm}$. No relationship was found between the average tumour size and $K R A S$ or GNAS mutation (WMD $=0.000,95 \% \mathrm{CI}$ -0.258 to $0.258, \mathrm{P}>0.999, \mathrm{Q}=0.860, I^{2}=0.000$ and WMD $=0.086,95 \% \mathrm{CI}-0.108$ to $0.280, \mathrm{P}=0.384$, $\mathrm{Q}=0.315, I^{2}=0.000$, respectively).

Macroscopic and microscopic duct types of IPMNs

Nine (Fritz et al. 2009; Hosoda et al. 2015; Kaino et al. 1999; Kobayashi et al. 2008; Kondo et al. 1997; Kuboki 


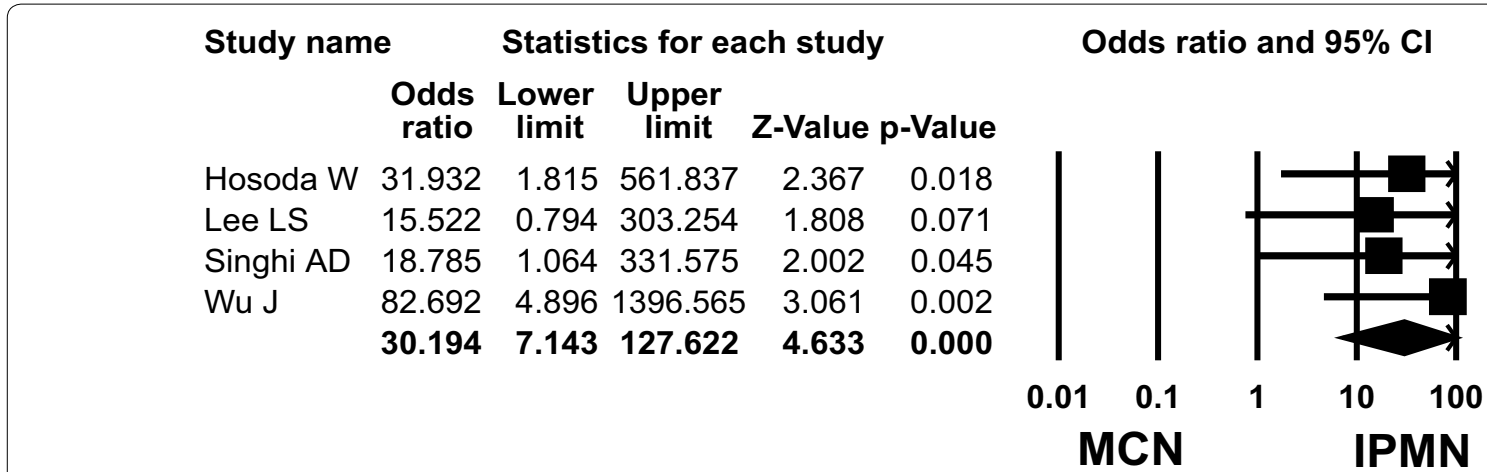

Fig. 2 Odds ratios with corresponding $95 \%$ confidence intervals of individual studies and pooled data for the association of GNAS mutation with intraductal papillary mucinous neoplasm (IPMN), compared with mucinous cystic neoplasm (MCN). Forest plot demonstrates the effect sizes and $95 \%$ Cls for each study and overall

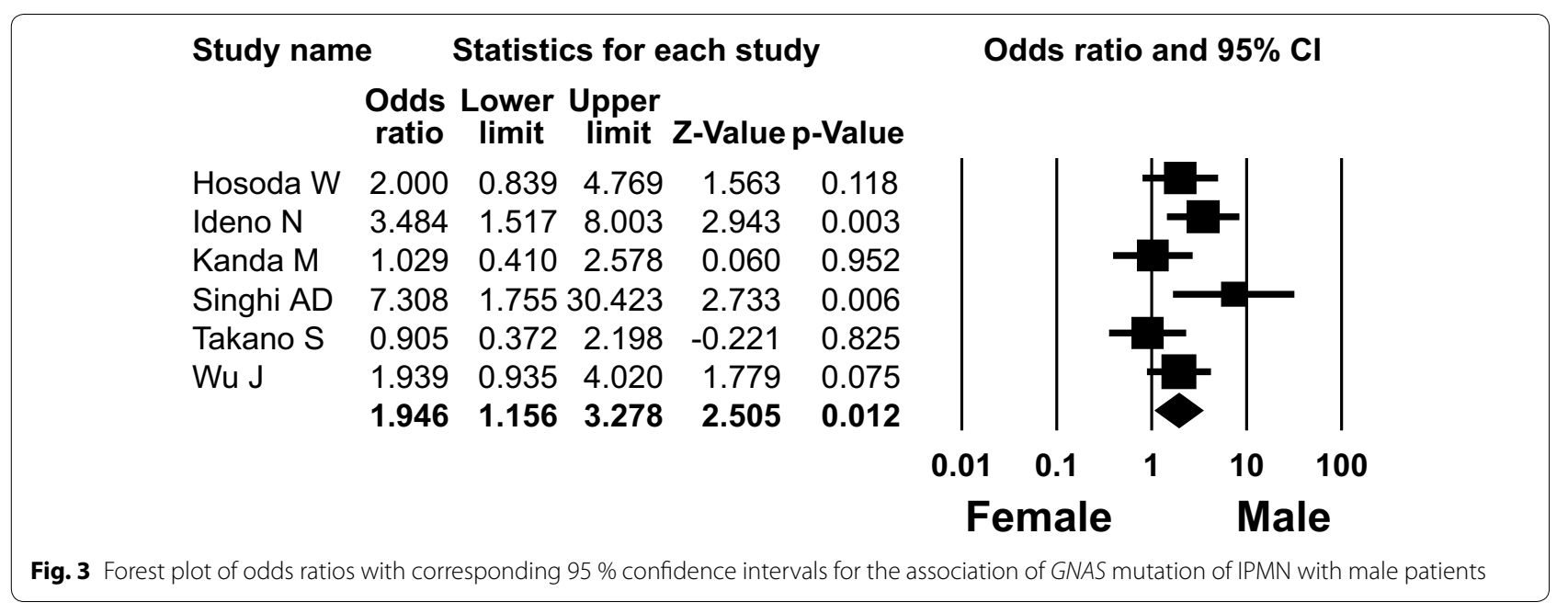

et al. 2015; Lee et al. 2014; Singhi et al. 2014; Wu et al. 2011b) and seven (Hosoda et al. 2015; Ideno et al. 2015; Kuboki et al. 2015; Lee et al. 2014; Singhi et al. 2014; Takano et al. 2014; Wu et al. 2011b) studies addressed KRAS and GNAS mutations in IPMN patients, according to the macroscopic duct type, respectively (Table 4). KRAS mutation was found in 97 (61\%) of 160 main duct type, 191 (70 \%) of 272 branch duct type, and 58 (62\%) of 94 mixed duct type. GNAS mutation was found in 105 (56\%) of 187 main duct type, 160 (49\%) of 327 branch duct type, and $45(51 \%)$ of 89 mixed duct type. KRAS and GNAS mutations were not significantly related to main (OR 0.614, $95 \%$ CI $0.342-1.102, P=0.102$, $\mathrm{Q}=10.686, I^{2}=34.496$ and OR $1.346,95 \%$ CI $0.934-$ $1.939, P=0.681, \mathrm{Q}=3.972, I^{2}=0.000$, respectively) and branch duct types (OR 1.662, $95 \%$ CI $0.859-3.216$, $P=0.132, \mathrm{Q}=13.149, I^{2}=46.764$ and $\mathrm{OR} 0.815$, $95 \%$ CI $0.585-1.136, P=0.577, \mathrm{Q}=4.743, I^{2}=0.000$, respectively).
Ten (Amato et al. 2014; Chadwick et al. 2009; Fritz et al. 2009; Hosoda et al. 2015; Jang et al. 2009; Kuboki et al. 2015; Mohri et al. 2012; Singhi et al. 2014; Tan et al. 2015; Wu et al. 2011b) and six (Amato et al. 2014; Hosoda et al. 2015; Kuboki et al. 2015; Singhi et al. 2014; Tan et al. 2015; Wu et al. 2011b) studies described KRAS and GNAS mutations in IPMN patients, according to the microscopic duct type, respectively (Table 5). KRAS mutation was detected in 228 (73\%) of 314 gastric type, 47 (72\%) of 65 pancreatobiliary duct type, 99 (44\%) of 227 intestinal type, and 5 (29\%) of 17 oncocytic type. KRAS mutation was significantly found in gastric type (OR 2.748; 95 \% CI 1.888-4.000; $P<0.001, Q=5.679$, $I^{2}=0.000$ ) with high frequency (Fig. 4), compared to its frequency in intestinal type (OR 0.311; $95 \%$ CI $0.206-$ $\left.0.471 ; P<0.001, \mathrm{Q}=10.036, I^{2}=10.324\right)$.

On the other hand, GNAS mutation was detected in 122 (74 \%) of 164 intestinal type, 137 (53\%) of 260 gastric type, 12 (24\%) of 49 pancreatobiliary duct type, and 
Table 4 Characteristics of individual studies of KRAS and GNAS mutations in patients with IPMN according to the macroscopic duct types

\begin{tabular}{|c|c|c|c|c|c|c|}
\hline \multirow[t]{2}{*}{ Study } & \multicolumn{3}{|c|}{ KRAS mutation (mutation/total) (\%) } & \multicolumn{3}{|c|}{ GNAS mutation (mutation/total) (\%) } \\
\hline & Main duct & Branch duct & Mixed duct & Main duct & Branch duct & Mixed duct \\
\hline Fritz S & $2 / 2(100)$ & $0 / 2(0)$ & $6 / 16(38)$ & & & \\
\hline Hosada W & $25 / 41(61)$ & $34 / 50(68)$ & & $26 / 41(63)$ & $29 / 50(58)$ & \\
\hline Ideno $\mathrm{N}$ & & & & 2/6 (33) & $22 / 45(49)$ & $7 / 11(64)$ \\
\hline Kaino M & $5 / 5(100)$ & $7 / 7(100)$ & & & & \\
\hline Kobayashi N & $1 / 2(50)$ & $12 / 20(60)$ & & & & \\
\hline Kondo H & $3 / 3(100)$ & $9 / 10(90)$ & & & & \\
\hline KubokiY & $29 / 50(58)$ & $42 / 81(52)$ & 25/41 (61) & $27 / 50(54)$ & $41 / 81(51)$ & $15 / 41(37)$ \\
\hline Lee LS & $3 / 9(33)$ & $6 / 10(60)$ & & 4/9 (44) & $4 / 10(40)$ & \\
\hline Singhi AD & $6 / 13(46)$ & 23/28 (82) & $6 / 9(67)$ & $4 / 13(31)$ & $11 / 28(39)$ & $3 / 9(33)$ \\
\hline Takano S & & & & 18/33 (55) & $16 / 49(33)$ & \\
\hline Wu J & 23/35 (66) & $58 / 64(91)$ & $21 / 28(75)$ & 24/35 (69) & $38 / 64$ (59) & $20 / 28(71)$ \\
\hline
\end{tabular}

Table 5 Characteristics of individual studies of KRAS and GNAS mutations in patients with IPMN according to the microscopic duct types

\begin{tabular}{|c|c|c|c|c|c|c|c|c|}
\hline \multirow[t]{2}{*}{ Study } & \multicolumn{4}{|c|}{ KRAS mutation (mutation/total) (\%) } & \multicolumn{4}{|c|}{ GNAS mutation (mutation/total) (\%) } \\
\hline & Gastric & Pancreato biliary & Intestinal & Oncocytic & Gastric & Pancreato biliary & Intestinal & Oncocytic \\
\hline Amato $\mathrm{E}$ & $5 / 6(83)$ & $3 / 3(100)$ & 14/36 (39) & $2 / 3(67)$ & $6 / 6(100)$ & 1/3 (33) & 30/36 (83) & 1/3 (33) \\
\hline Chadwick B & $16 / 19(84)$ & $6 / 7(86)$ & $15 / 26(58)$ & & & & & \\
\hline Fritz S & $7 / 10(70)$ & & $1 / 7(14)$ & $0 / 2(0)$ & & & & \\
\hline Hosada W & $40 / 55(73)$ & $6 / 7(86)$ & $12 / 27(44)$ & $1 / 2(50)$ & $34 / 55(62)$ & $0 / 7(0)$ & $21 / 27(74)$ & $0 / 2(0)$ \\
\hline Jang JY & $5 / 13(38)$ & $4 / 8(50)$ & $4 / 19(21)$ & & & & & \\
\hline Kuboki Y & 63/97 (65) & 7/11 (64) & $25 / 56(45)$ & 1/8 (13) & 45/97 (46) & $3 / 11(27)$ & $33 / 56(59)$ & 1/8 (13) \\
\hline Mohri D & $9 / 11(82)$ & $1 / 1(100)$ & $3 / 11(27)$ & $1 / 2(50)$ & & & & \\
\hline Singhi AD & $30 / 40(75)$ & $3 / 5(60)$ & $2 / 5(40)$ & & 13/40 (33) & 0/5 (0) & $5 / 5(100)$ & \\
\hline Tan MC & $8 / 10(80)$ & 10/16 (63) & $17 / 27(63)$ & & $5 / 10(50)$ & $5 / 16(31)$ & $20 / 27(74)$ & \\
\hline Wu J & $45 / 52(87)$ & $7 / 7$ (100) & $6 / 13(46)$ & & $34 / 52(65)$ & 3/7 (43) & $13 / 13(100)$ & \\
\hline
\end{tabular}

$2(15 \%)$ of 13 oncocytic type. GNAS mutation was significantly found in intestinal type with high frequency (OR 2.955; 95 \% CI 1.771-4.929; $P<0.001, Q=5.537$, $I^{2}=9.694$ ) (Fig. 5) and was present in pancreatobiliary and oncocytic types with low frequency (OR 0.220; $95 \%$ CI $0.108-0.450 ; P<0.001, Q=3.009, I^{2}=0.000$ and OR 0.128; $95 \%$ CI $0.031-0.537 ; P=0.005, Q=0.033$, $I^{2}=0.000$, respectively).

However, KRAS mutation was not significantly associated with pancreatobiliary and oncocytic types, respectively (OR 1.604, $95 \%$ CI $0.873-2.947, P=0.128$, $\mathrm{Q}=4.971, I^{2}=0.000$ and OR 0.415 ; $95 \%$ CI $0.129-$ 1.336; $P=0.140, \mathrm{Q}=3.643, I^{2}=0.000$, respectively). GNAS mutation was not significantly associated with gastric type (OR $0.845,95 \%$ CI $0.560-1.275, P=0.422$, $\mathrm{Q}=3.189, I^{2}=0.000$, respectively).
Histologic grade and presence of adenocarcinoma Nine (Amato et al. 2014; Chadwick et al. 2009; Fritz et al. 2009; Hosoda et al. 2015; Kuboki et al. 2015; Lubezky et al. 2011; Schönleben et al. 2008; Singhi et al. 2014; Wu et al. 2011b) and seven (Amato et al. 2014; Hosoda et al. 2015; Ideno et al. 2015; Kanda et al. 2013; Kuboki et al. 2015; Singhi et al. 2014; Wu et al. 2011b) studies presented KRAS and GNAS mutations of IPMN patients, according to the histologic grades. KRAS mutation was detected in 132 (58\%) of 227 high grade, 95 (70\%) of 136 intermediate grade, and 129 (63\%) of 205 low grade. KRAS mutation was detected in high grade dysplasia with lower frequency (OR 0.626; 95 \% CI 0.408-0.961; $P=0.032, \mathrm{Q}=7.797, I^{2}=10.219$ ) (Fig. 6).

However, the prevalence of KRAS mutation in low and intermediate grades was not statistically significant 


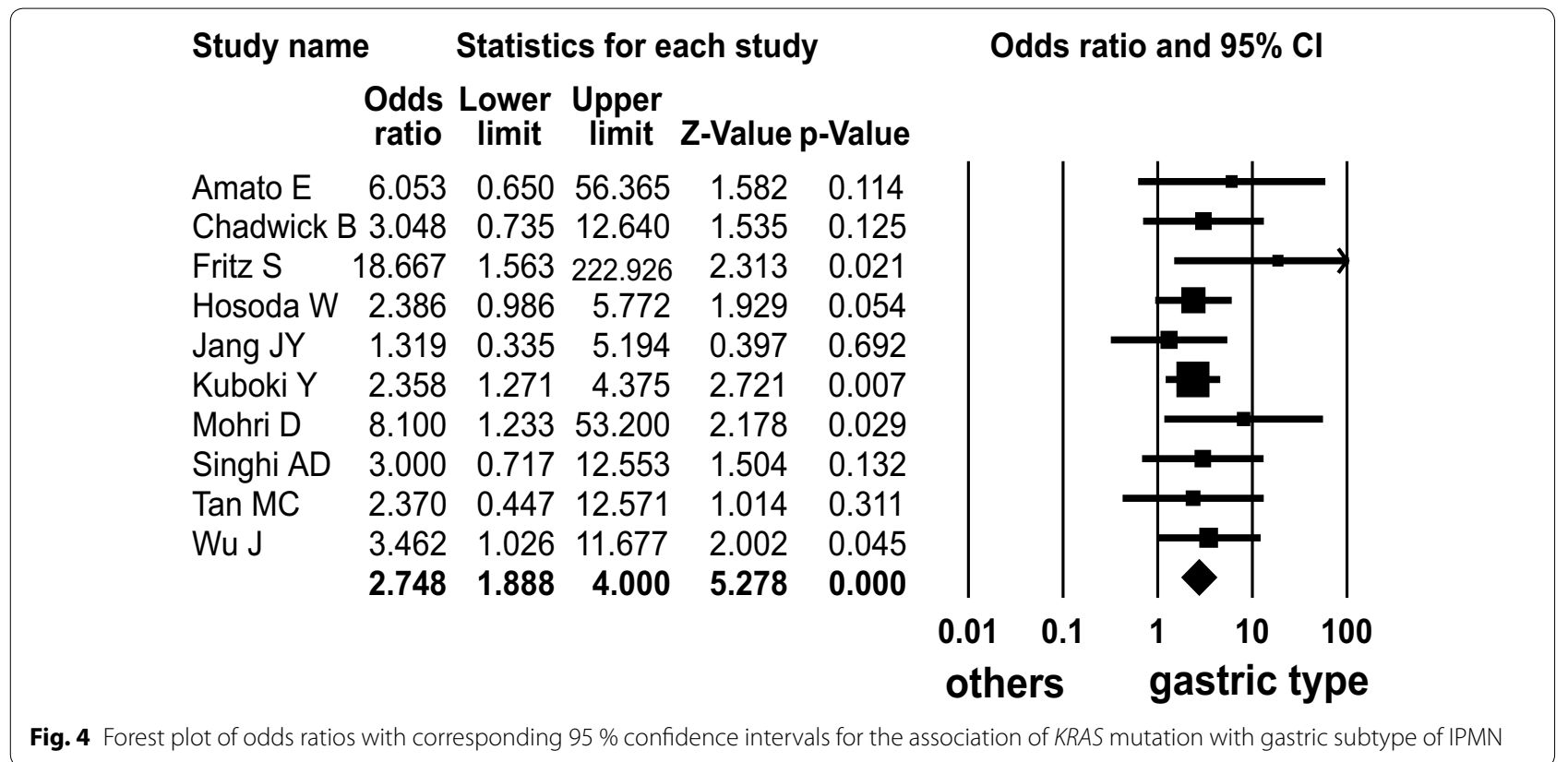

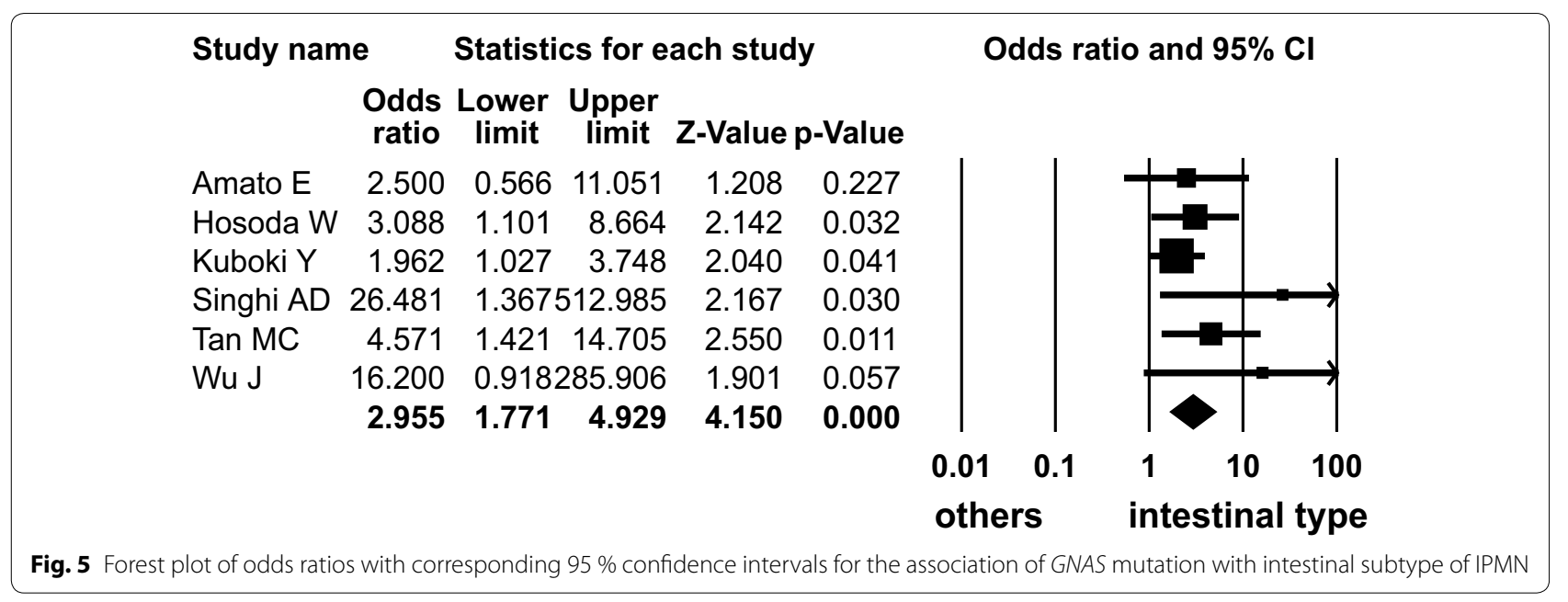

(OR 1.521, 95 \% CI 0.984-2.353, $P=0.059, \mathrm{Q}=1.929$, $I^{2}=0.000$, and OR 1.139, $95 \%$ CI 0.657-1.976, $P=0.643$, $\mathrm{Q}=8.326, I^{2}=15.929$, respectively). GNAS mutation was detected in 120 (61\%) of 198 high grade, 86 (67\%) of 128 intermediate grade, and 119 (56\%) of 213 low grade. The frequency of GNAS mutation did not differ among high, intermediate, and low grades of IPMN patients (OR 0.769, 95 \% CI 0.382-1.547, $P=0.461, \mathrm{Q}=15.126$, $I^{2}=60.334$; OR 1.273, $95 \%$ CI $0.786-2.060, P=0.326$, $\mathrm{Q}=2.789, I^{2}=0.000$, and OR $0.938,95 \%$ CI $0.500-$ 1.761, $P=0.843, \mathrm{Q}=12.357, I^{2}=51.445$, respectively). The subgroup analysis revealed that the detection methods influenced the relationship between GNAS mutation and high grade dysplasia of IPMN (Additional file 2: Table S2).

Twenty-one (Amato et al. 2014; Fritz et al. 2009; Hosoda et al. 2015; Ideno et al. 2015; Jang et al. 2009; Kondo et al. 1997; Kuboki et al. 2015; Lubezky et al. 2011; Mizuno et al. 2010; Mohri et al. 2012; Mueller et al. 2003; Mulligan et al. 1999; Nakata et al. 2002; Raimondo et al. 2002; Schönleben et al. 2008; Sessa et al. 1994; Singhi et al. 2014; Uemura et al. 2003; Wada et al. 2004; Wu et al. 2011b; Yoshizawa et al. 2002) and six (Amato et al. 2014; Hosoda et al. 2015; Ideno et al. 2015; Kuboki et al. 2015; Singhi et al. 2014; Wu et al. 2011b) studies reported KRAS and GNAS mutations in IPMN patients, according 


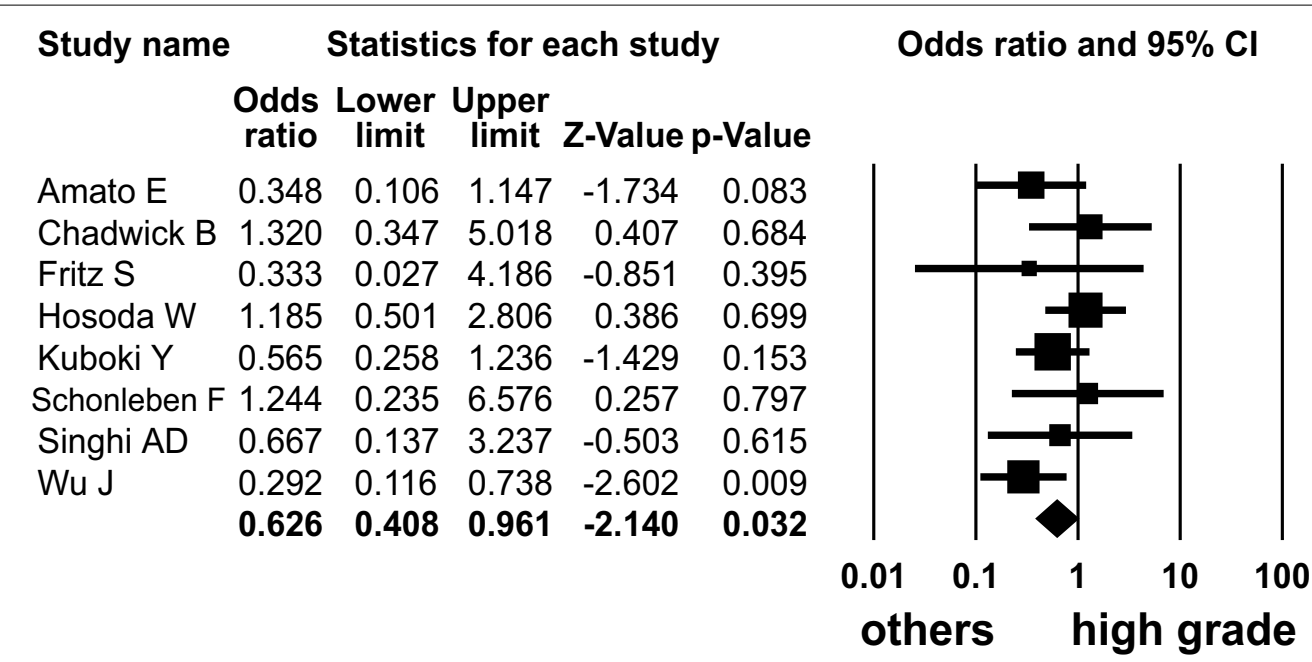

Fig. 6 Forest plot of odds ratios with corresponding $95 \%$ confidence intervals for the association of KRAS mutation with high-grade dysplasia of IPMN

to the presence of associated pancreatic adenocarcinoma. KRAS mutation was present in 190 (64\%) of 297 IPMN patients with invasive adenocarcinoma, whereas 388 (63 \%) of 620 IPMNs without adenocarcinoma. GNAS mutation was present in 80 (51\%) of 157 IPMN patients with invasive adenocarcinoma, whereas 265 (59\%) of 446 IPMNs without adenocarcinoma. No significant associations were seen between $K R A S$ and GNAS mutations and the presence of adenocarcinoma in IPMN patients (OR 1.342, $95 \%$ CI 0.878-2.050, $P=0.174$, $\mathrm{Q}=26.746, I^{2}=25.222$, and OR 0.548, $95 \%$ CI 0.285$1.053, P=0.071, \mathrm{Q}=10.231, I^{2}=51.131$, respectively). The subgroup analyses disclosed that the ethnicity and detection methods of these mutations did not influence the relationship between GNAS mutation and IPMNassociated adenocarcinoma (Additional file 2: Table S2).

\section{Sensitivity analysis and publication bias}

The sensitivity analyses showed that none of the studies affected the pooled prevalence rate, OR, or WMD with CIs, except the pooled analysis of GNAS mutation between the genders and of KRAS mutation between high grade and the other grades of IPMNs (Additional file 3: Fig. S1). Through the funnel plots and the Egger's regression tests, the pooled results from KRAS mutation between tumour locations within the pancreas, GNAS mutation between mean tumour size and between intermediate grade and the other grades, and KRAS and GNAS mutations between microscopic duct subtypes of IPMNs showed the possibility of publication bias. However, other pooled analyses showed no evidence of publication bias (Additional file 4: Table S3) (Additional file 5: Fig. S2).

\section{Discussion}

This pooled analysis using data from 1253, 835, and 143 pancreatic IPMN patients revealed that overall KRAS, GNAS, and RNF43 mutations were detected in 61, 56, and $23 \%$, respectively. These gene mutation rates did not differ according to the ethnicity, detection methods, and specimen type. This meta-analysis showed that the frequencies of KRAS and GNAS mutations in IPMN patients were considerably variable among microscopic duct subtypes.

The most common preoperative challenge is to distinguish IPMN from other cystic lesions of the pancreas. There are three primary types of pancreatic cystic neoplasm: IPMN, MCN, and SCA (Wu et al. 2011b). Most of the pancreatic adenocarcinomas develop from IPMNs, followed by MCNs. In contrast, SCAs do not give rise to invasive adenocarcinomas (Wu et al. 2011b). Until now, preoperative cystic fluid evaluation for CEA, amylase, DNA methylation, and microRNA expression remains suboptimal, partly because of their lack of disease specificity (Weinstein et al. 2004). Based on the high frequencies and significant ORs of KRAS and GNAS mutations in IPMNs compared to the other cystic lesions, particularly MCNs, the combined detection of KRAS and GNAS mutations from the cystic fluid would be highly valuable in the preoperative diagnosis of IPMNs.

This pooled analysis found that different mutational profile between $K R A S$ and GNAS was significantly related to the microscopic subtypes of IPMNs, which are a determinant for the subtypes of invasive adenocarcinomas. Over $30 \%$ of intestinal and pancreaticobiliary type IPMNs develop colloid and tubular type adenocarcinomas, respectively (Klöppel et al. 2014). In contrast, gastric 
type IPMNs rarely develops into invasive adenocarcinomas. When gastric type IPMNs progress to adenocarcinomas, it is the tubular type (Klöppel et al. 2014). The IPMNs with colloid adenocarcinoma is known to have a better prognosis than those with tubular adenocarcinoma (Klöppel et al. 2014; Tan et al. 2015). Colloid adenocarcinomas arising from IPMNs were associated with a high frequency of GNAS mutation (Tan et al. 2015). In agreement with the previous study (Tan et al. 2015), our results suggest that $K R A S$ and GNAS mutational pattern may represent different pathways in the IPMN-adenocarcinoma sequence.

The GNAS gene encodes the $\alpha$-subunit of the stimulatory G-protein (Gos). Somatic activating GNAS mutation results in an elevated level of cyclic adenosine monophosphate (cAMP) and in uncontrolled growth signalling (Landis et al. 1989; Weinstein et al. 2004). GNAS mutation has been found in various tumours, fibrous dysplasia, and McCune-Albright syndrome (Landis et al. 1989; Weinstein et al. 2004). Interestingly, most of the GNAS mutations at codon 201 in IPMNs result in either an $\mathrm{R} 201 \mathrm{H}$ or an R201C substitution, which are the same mutation as in endocrine neoplasms (Landis et al. 1989; Weinstein et al. 2004). The endocrine tumours with activating GNAS mutations have been supposed to be associated with hormonal secretion.

Recently, inactivating nonsense mutations of RNF43 gene that encodes a protein with E3 ubiquitin ligase activity were found in IPMNs (Amato et al. 2014; Macgregor-Das and Iacobuzio-Donahue 2013; Sakamoto et al. 2015; Tan et al. 2015; Wu et al. 2011a). Our metaanalysis found that RNF43 mutation was not associated with clinicopathologic parameters of patients with IPMN (Additional file 6: Table S4). Due to the lack of published articles, further studies need to clarify the roles and characteristics of RNF43 mutation in IPMN patients.

This meta-analysis revealed that KRAS and GNAS mutations are not associated with the malignant potential or prognosis in patients with IPMN. This meta-analysis showed that frequency of $K R A S$ mutation was rather lower in high-grade dysplasia than low- and/or intermediate-grade dysplasia. However, further more studies are needed to confirm the results. The frequency of GNAS mutation in IPMN patients did not differ among the three grades of dysplasia and in the absence or presence of associated adenocarcinoma. The association between GNAS mutation and the prognosis of patients with IPMN has been the subject of considerable controversy. GNAS mutation was significantly associated with high-grade dysplasia (Wu et al. 2011b), whereas wild-type GNAS in IPMNs was significantly related to the development of adenocarcinoma (Ideno et al. 2015). However, as with this meta-analysis, other studies failed to show significant relationships between GNAS mutation, dysplasia grades, and the presence of adenocarcinoma (Amato et al. 2014; Hosoda et al. 2015; Kuboki et al. 2015; Singhi et al. 2014).

It has been well known that pancreatic cancers are more frequent in Ashkenazi Jews and African groups. However, the frequency of IPMN between races has not been known because of its rare incidence. Therefore, we simply classified IPMN patients into the Caucasian and Asian groups in this study, although the genetic changes of diverse and detailed ethnicity would be an interesting issue and broaden the novel biological pathway of IPMN.

The present meta-analysis has some limitations. First, the possibility of publication bias could not be completely excluded. Second, the individual study used in this metaanalysis was done with relatively small sample sizes, due to the rare occurrence of IPMNs. Lastly, the different studies did not only use different methods for mutation detection but also different tumour materials, such as cystic fluid versus tissue specimen. This might confound the mutation detection rates.

In summary, this meta-analysis provides sensitive and specific diagnostic roles of KRAS and GNAS mutations for detecting the IPMN among the pancreatic cystic lesions. Furthermore, KRAS and GNAS mutations hint a possibility that patients with IPMN have which form of microscopic subtype.

\section{Additional files}

Additional file 1: Table S1. Characteristics of individual studies of RNF43 mutation in IPMN.

Additional file 2: Table S2. Subgroup analysis of histologic grades and associated adenocarcinoma according to the ethnicity and detection methods in IPMN patients with GNAS mutation.

Additional file 3: Fig. S1. Sensitivity analysis of meta-analysis for KRAS mutation between high grade and the other low and intermediate grades of IPMN. When each study is sequentially removed and meta-analysis is repeated with the remaining studies, the pooled odd ratios remain the same.

Additional file 4: Table S3. Egger's tests for funnel plot asymmetry. Additional file 5: Fig. S2. Funnel plot for publication bias in the frequency of KRAS mutation between the main duct and branch duct of IPMN. Individual studies are represented by small circles. An area of the inverted $\mathrm{V}$-shape is devoid of small negative studies, indicating publication bias.

Additional file 6: Table S4. Association between RNF43 mutation and clinicopathologic parameters of IPMN.

\section{Authors' contributions}

JHL collected the data and wrote the manuscript. YK and JWC collected the data and discussed the study results. YSK designed the study and edited the manuscript. All authors have read and approved the final manuscript.

\section{Acknowledgements}

This work was supported in part by Mid-career Researcher Program (Grant No. 2016 R1A2B4012030) and Basic Science Research Program (Grant No. 2013 
R1A1A1058146) through National Research Foundation of Korea (NRF) funded by the Ministry of Science, ICT, and Future Planning.

\section{Competing interests}

The authors declare that they have no competing interests.

\section{Received: 2 May 2016 Accepted: 15 July 2016}

Published online: 26 July 2016

\section{References}

Amato E, Molin MD, Mafficini A, Yu J, Malleo G, Rusev B, Fassan M, Antonello D, Sadakari Y, Castelli P, Zamboni G, Maitra A, Salvia R, Hruban RH, Bassi C, Capelli P, Lawlor RT, Goggins M, Scarpa A (2014) Targeted next-generation sequencing of cancer genes dissects the molecular profiles of intraductal papillary neoplasms of the pancreas. J Pathol 233:217-227. doi:10.1002/ path.4344

Chadwick B, Willmore-Payne C, Tripp S, Layfield LJ, Hirschowitz S, Holden J (2009) Histologic, immunohistochemical, and molecular classification of 52 IPMNs of the pancreas. Appl Immunohistochem Mol Morphol 17:31-39. doi:10.1097/PAl.0b013e31817c02c6

Chang X, Jiang Y, Li J, Chen J (2014) Intraductal tubular adenomas (pyloric gland-type) of the pancreas: clinicopathologic features are similar to gastric-type intraductal papillary mucinous neoplasms and different from intraductal tubulopapillary neoplasms. Diagn Pathol 9:172. doi:10.1186/ s13000-014-0172-1

Fritz S, Fernandez-del Castillo C, Mino-Kenudson M, Crippa S, Deshpande V, Lauwers GY, Warshaw AL, Thayer SP, lafrate AJ (2009) Global genomic analysis of intraductal papillary mucinous neoplasms of the pancreas reveals significant molecular differences compared to ductal adenocarcinoma. Ann Surg 249:440-447. doi:10.1097/SLA.0b013e31819a6e16

Furukawa T, Fujisaki R, Yoshida Y, Kanai N, Sunamura M, Abe T, Takeda K, Matsuno S, Horii A (2005) Distinct progression pathways involving the dysfunction of DUSP6/MKP-3 in pancreatic intraepithelial neoplasia and intraductal papillary-mucinous neoplasms of the pancreas. Mod Pathol 18:1034-1042. doi:10.1038/modpathol.3800383

Hosoda W, Sasaki E, Murakami Y, Yamao K, Shimizu Y, Yatabe Y (2015) GNAS mutation is a frequent event in pancreatic intraductal papillary mucinous neoplasms and associated adenocarcinomas. Virchows Arch 466:665674. doi:10.1007/s00428-015-1751-6

Ideno N, Ohtsuka T, Matsunaga T, Kimura H, Watanabe Y, Tamura K, Aso T, Aishima S, Miyasaka Y, Ohuchida K, Ueda J, Takahata S, Oda Y, Mizumoto K, Tanaka M (2015) Clinical significance of GNAS mutation in intraductal papillary mucinous neoplasm of the pancreas with concomitant pancreatic ductal adenocarcinoma. Pancreas 44:311-320. doi:10.1097/ MPA.0000000000000258

Jang JY, Park YC, Song YS, Lee SE, Hwang DW, Lim CS, Lee HE, Kim WH, Kim SW (2009) Increased K-ras mutation and expression of S100A4 and MUC2 protein in the malignant intraductal papillary mucinous tumour of the pancreas. J Hepatobiliary Pancreat Surg 16:668-674. doi:10.1007/ s00534-009-0105-7

Kaino M, Kondoh S, Okita S, Hatano S, Shiraishi K, Kaino S, Okita K (1999) Detection of K-ras and p53 gene mutations in pancreatic juice for the diagnosis of intraductal papillary mucinous tumours. Pancreas 18:294-299. doi:10.1097/00006676-199904000-00011

Kanda M, Knight S, Topazian M, Syngal S, Farrell J, Lee J, Kamel I, Lennon AM, Borges M, Young A, Fujiwara S, Seike J, Eshleman J, Hruban RH, Canto MI, Goggins M (2013) Mutant GNAS detected in duodenal collections of secretin-stimulated pancreatic juice indicates the presence or emergence of pancreatic cysts. Gut 62:1024-1033. doi:10.1136/gutjnl-2012-302823

Kitago M, Ueda M, Aiura K, Suzuki K, Hoshimoto S, Takahashi S, Mukai M, Kitajima M (2004) Comparison of K-ras point mutation distributions in intraductal papillary-mucinous tumours and ductal adenocarcinoma of the pancreas. Int J Cancer 110:177-182. doi:10.1002/ijc.20084

Klöppel G, Kosmahl M (2001) Cystic lesions and neoplasms of the pancreas. The features are becoming clearer. Pancreatology 1:648-655. doi:10.1159/000055876

Klöppel G, Basturk O, Schlitter AM, Konukiewitz B, Esposito I (2014) Intraductal neoplasms of the pancreas. Semin Diagn Pathol 31:452-466. doi:10.1053/j.semdp.2014.08.005
Kobayashi N, Inamori M, Fujita K, Fujisawa T, Fujisawa N, Takahashi H, Yoneda M, Abe Y, Kawamura H, Shimamura T, Kirikoshi H, Kubota K, Sakaguchi T, Saito S, Saubermann LJ, Nakajima A (2008) Characterization of K-ras gene mutations in association with mucinous hypersecretion in intraductal papillary-mucinous neoplasms. J Hepatobiliary Pancreat Surg 15:169177. doi:10.1007/s00534-007-1223-8

Kondo H, Sugano K, Fukayama N, Hosokawa K, Ohkura H, Ohtsu A, Mukai K, Yoshida S (1997) Detection of K-ras gene mutations at codon 12 in the pancreatic juice of patients with intraductal papillary mucinous tumours of the pancreas. Cancer 79:900-905. doi:10.1002/ (SICI) 1097-0142(19970301)79:5<900:AID-CNCR5>3.0.CO;2-F

Kuboki Y, Shimizu K, Hatori T, Yamamoto M, Shibata N, Shiratori K, Furukawa T (2015) Molecular biomarkers for progression of intraductal papillary mucinous neoplasm of the pancreas. Pancreas 44:227-235. doi:10.1097/ MPA.0000000000000253

Landis CA, Masters SB, Spada A, Pace AM, Bourne HR, Vallar L (1989) GTPase inhibiting mutations activate the alpha chain of Gs and stimulate adenylyl cyclase in human pituitary tumours. Nature 340:692-696. doi:10.1038/340692a0

Lee JH, Choi JW, Kim YS (2011) Frequencies of BRAF and NRAS mutations are different in histological types and sites of origin of cutaneous melanoma: a meta-analysis. Br J Dermatol 164:776-784. doi:10.1111/j.1365-2133.2010.10185.x

Lee LS, Doyle LA, Houghton J, Sah S, Bellizzi AM, Szafranska-Schwarzbach AE, Conner JR, Kadiyala V, Suleiman SL, Banks PA, Andruss BF, Conwell DL (2014) Differential expression of GNAS and KRAS mutations in pancreatic cysts. JOP 15:581-586. doi:10.6092/1590-8577/2432

Lubezky N, Ben-Haim M, Marmor S, Brazowsky E, Rechavi G, Klausner JM, Cohen Y (2011) High-throughput mutation profiling in intraductal papillary mucinous neoplasm (IPMN). J Gastrointest Surg 15:503-511. doi:10.1007/s11605-010-1411-8

Macgregor-Das AM, lacobuzio-Donahue CA (2013) Molecular pathways in pancreatic carcinogenesis. J Surg Oncol 107:8-14. doi:10.1002/jso.23213

Mizuno O, Kawamoto H, Yamamoto N, Horiguchi S, Tsutsumi K, Fujii M, Kato H, Hirao K, Kurihara N, Ishida E, Ogawa T, Okada H, Yamamoto K (2010) Single-pattern convergence of K-ras mutation correlates with surgical indication of intraductal papillary mucinous neoplasms. Pancreas 39:617-621. doi:10.1097/MPA.0b013e3181c75d9b

Mohri D, Asaoka Y, ljichi H, Miyabayashi K, Kudo Y, Seto M, Ohta M, Tada M, Tanaka Y, Ikenoue T, Tateishi K, Isayama H, Kanai F, Fukushima N, Tada M, Kawabe T, Omata M, Koike K (2012) Different subtypes of intraductal papillary mucinous neoplasm in the pancreas have distinct pathways to pancreatic cancer progression. J Gastroenterol 47:203-213. doi:10.1007/ s00535-011-0482-y

Mueller J, Gansauge S, Mattfeldt T (2003) P53 mutation but not p16/MTS1 mutation occurs in intraductal papillary mucinous tumours of the pancreas. Hepatogastroenterology 50:541-544

Mulligan NJ, Yang S, Andry C, Klein M, O'Brien MJ (1999) The role of p21 ras in pancreatic neoplasia and chronic pancreatitis. Hum Pathol 30:602-610

Nakata B, Yashiro M, Nishioka N, Aya M, Yamada S, Takenaka C, Ohira M, Ishikawa T, Nishino H, Wakasa K, Hirakawa K (2002) Genetic alterations in adenoma-carcinoma sequencing of intraductal papillary-mucinous neoplasm of the pancreas. Int J Oncol 21:1067-1072. doi:10.3892/ ijo.21.5.1067

Paal E, Thompson LD, Przygodzki RM, Bratthauer GL, Heffess CS (1999) A clinicopathologic and immunohistochemical study of 22 intraductal papillary mucinous neoplasms of the pancreas, with a review of the literature. Mod Pathol 12:518-528

Raimondo M, Tachibana I, Urrutia R, Burgart LJ, DiMagno EP (2002) Invasive cancer and survival of intraductal papillary mucinous tumours of the pancreas. Am J Gastroenterol 97:2553-2558. doi:10.1111/j.1572-0241.2002.06022.x

Reid MD, Saka B, Balci S, Goldblum AS, Adsay NV (2014) Molecular genetics of pancreatic neoplasms and their morphologic correlates: an update on recent advances and potential diagnostic applications. Am J Clin Pathol 141:168-180. doi:10.1309/AJCPOFKDP7ENVKEV

Sakamoto H, Kuboki Y, Hatori T, Yamamoto M, Sugiyama M, Shibata N, Shimizu K, Shiratori K, Furukawa T (2015) Clinicopathological significance of somatic RNF43 mutation and aberrant expression of ring finger protein 43 in intraductal papillary mucinous neoplasms of the pancreas. Mod Pathol 28:261-267. doi:10.1038/modpathol.2014.98 
Schönleben F, Allendorf JD, Qiu W, Li X, Ho DJ, Ciau NT, Fine RL, Chabot JA, Remotti HE, Su GH (2008) Mutational analyses of multiple oncogenic pathways in intraductal papillary mucinous neoplasms of the pancreas. Pancreas 36:168-172. doi:10.1097/MPA.0b013e318158a4d2

Sessa F, Solcia E, Capella C, Bonato M, Scarpa A, Zamboni G, Pellegata NS, Ranzani GN, Rickaert F, Klöppel G (1994) Intraductal papillary-mucinous tumours represent a distinct group of pancreatic neoplasms: an investigation of tumour cell differentiation and K-ras, p53 and c-erbB-2 abnormalities in 26 patients. Virchows Arch 425:357-367

Siddiqui AA, Kowalski TE, Kedika R, Roy A, Loren DE, Ellsworth E, Adler D, Finkelstein SD (2013) EUS-guided pancreatic fluid aspiration for DNA analysis of KRAS and GNAS mutations for the evaluation of pancreatic cystic neoplasia: a pilot study. Gastrointest Endosc 77:669-670. doi:10.1016/j. gie.2012.11.009

Singhi AD, Nikiforova MN, Fasanella KE, McGrath KM, Pai RK, Ohori NP, Bartholow TL, Brand RE, Chennat JS, Lu X, Papachristou Gl, Slivka A, Zeh HJ, Zureikat AH, Lee KK, Tsung A, Mantha GS, Khalid A (2014) Preoperative GNAS and KRAS testing in the diagnosis of pancreatic mucinous cysts. Clin Cancer Res 20:4381-4389. doi:10.1158/1078-0432.CCR-14-0513

Tada M, Omata M, Ohto M (1991) Ras gene mutations in intraductal papillary neoplasms of the pancreas. Analysis in five cases. Cancer 67:634-637. doi:10.1002/1097-0142(19910201)67:3<634:AID-CNCR2820670318>3.0. $\mathrm{CO} ; 2-7$

Takano S, Fukasawa M, Maekawa S, Kadokura M, Miura M, Shindo H, Takahashi E, Sato T, Enomoto N (2014) Deep sequencing of cancer-related genes revealed GNAS mutations to be associated with intraductal papillary mucinous neoplasms and its main pancreatic duct dilation. PLoS One 9:e98718. doi:10.1371/journal.pone.0098718

Tan MC, Basturk O, Brannon AR, Bhanot U, Scott SN, Bouvier N, LaFemina J, Jarnagin WR, Berger MF, Klimstra D, Allen PJ (2015) GNAS and KRAS mutations define separate progression pathways in intraductal papillary mucinous neoplasm-associated carcinoma. J Am Coll Surg 220:845-854. doi:10.1016/j.jamcollsurg.2014.11.029
Uemura K, Hiyama E, Murakami Y, Kanehiro T, Ohge H, Sueda T, Yokoyama T (2003) Comparative analysis of K-ras point mutation, telomerase activity, and p53 overexpression in pancreatic tumours. Oncol Rep 10:277-283. doi:10.3892/or.10.2.277

Wada K, Takada T, Yasuda H, Amano H, Yoshida M, Sugimoto M, Irie H (2004) Does "clonal progression" relate to the development of intraductal papillary mucinous tumours of the pancreas? J Gastrointest Surg 8:289-296. doi:10.1016/j.gassur.2003.09.027

Weinstein LS, Liu J, Sakamoto A, Xie T, Chen M (2004) Minireview: GNAS—normal and abnormal functions. Endocrinology 145:5459-5464. doi:10.1210/ en.2004-0865

Wu J, Jiao Y, Dal Molin M, Maitra A, de Wilde RF, Wood LD, Eshleman JR, Goggins MG, Wolfgang CL, Canto MI, Schulick RD, Edil BH, Choti MA, Adsay V, Klimstra DS, Offerhaus GJ, Klein AP, Kopelovich L, Carter H, Karchin R, Allen PJ, Schmidt CM, Naito Y, Diaz LA Jr, Kinzler KW, Papadopoulos N, Hruban RH, Vogelstein B (2011a) Whole-exome sequencing of neoplastic cysts of the pancreas reveals recurrent mutations in components of ubiquitin-dependent pathways. Proc Natl Acad Sci USA 108:21188-21193. doi:10.1073/pnas. 1118046108

Wu J, Matthaei H, Maitra A, Dal Molin M, Wood LD, Eshleman JR, Goggins M, Canto MI, Schulick RD, Edil BH, Wolfgang CL, Klein AP, Diaz LA Jr, Allen PJ, Schmidt CM, Kinzler KW, Papadopoulos N, Hruban RH, Vogelstein B (2011b) Recurrent GNAS mutations define an unexpected pathway for pancreatic cyst development. Sci Transl Med 3:92ra66. doi:10.1126/ scitransImed. 3002543

Yoshizawa K, Nagai H, Sakurai S, Hironaka M, Morinaga S, Saitoh K, Fukayama M (2002) Clonality and K-ras mutation analyses of epithelia in intraductal papillary mucinous tumour and mucinous cystic tumour of the pancreas. Virchows Arch 441:437-443. doi:10.1007/s00428-002-0645-6

\section{Submit your manuscript to a SpringerOpen ${ }^{\circ}$ journal and benefit from:}

- Convenient online submission

Rigorous peer review

- Immediate publication on acceptance

- Open access: articles freely available online

- High visibility within the field

- Retaining the copyright to your article

Submit your next manuscript at $\boldsymbol{\nabla}$ springeropen.com 